\title{
Origin of abiotic hydrocarbon in the deep mantle by carbonate breakdown is regulated by hydrogen sulphide
}

\author{
*Shubham Choudhary ${ }^{1}$, Koushik Sen ${ }^{1}$, Souvik Das ${ }^{2}$, \\ Santosh Kumar ${ }^{3}$ \\ ${ }^{1}$ Wadia Institute of Himalayan Geology; 33, GMS Road, \\ Dehradun-248001, India \\ ${ }^{2}$ Department of Earth \& Environmental Sciences, University \\ of Texas at Arlington, TX, USA \\ ${ }^{3}$ Department of Geology, Kumaun University, Nainital, India \\ *correspondence: shubham.geologist55@gmail.com
}

Breakdown of carbonates sourced from subducted oceanic crust generates abiotic hydrocarbon in the deep mantle. This is an integral part of the global carbon cycle and has drawn much attention in recent times. Here we report rare deep mantle fluid inclusions in a pyroxenite, associated with the Kerguelen Plume in northeast India. Raman spectroscopy reveals primary inclusions of $\mathrm{CH}$ fluid and calcite in $\mathrm{Cpx}$ phenocryst of this pyroxenite. One of the cumulates of $\mathrm{Cpx}$ from the same rock contains primary fluid inclusions of hydrogen sulphide $\left(\mathrm{H}_{2} \mathrm{~S}\right)$, carbon monoxide $(\mathrm{CO})$, rutile and calcite. We infer the formation of abiotic $\mathrm{CH}$ from breakdown of calcite in highly reduced mantle and their subsequent entrapment in the phenocrystic Cpx. We further suggest that carbonate breakdown in the reduced deep mantle not necessarily forms $\mathrm{CH}$. On the contrary, presence of $\mathrm{H}_{2} \mathrm{~S}$, due to its buffering capacity, will help form CO instead. 